\title{
An information system supporting cap and trade in organizations
}

Chesney, Marc ; Maranghino-Singer, Brigitte ; Huber, Martina Z ; Oertle, David ; Hilty, Lorenz M

\begin{abstract}
We present a software system to create and implement internal markets in organizations that want to limit the $\mathrm{CO} 2$ emissions or the use of scarce resources by their employees. This system can be applied to domains such as business travel by distributing a limited number of permits for business travel-related $\mathrm{CO} 2$ emissions at the beginning of a period and then allowing the permits to be traded inside the organization. The system calculates the $\mathrm{CO} 2$ emissions caused by planned trips and provides the market mechanisms to trade the permits. The approach can be generalized from emission permits to any scarce good that is assigned by the management to units or individual members of the organization, such as parking spaces. Both cases are described by way of detailed examples.
\end{abstract}

DOI: https://doi.org/10.1007/978-3-319-09228-7_17

Posted at the Zurich Open Repository and Archive, University of Zurich

ZORA URL: https://doi.org/10.5167/uzh-109997

Book Section

Accepted Version

Originally published at:

Chesney, Marc; Maranghino-Singer, Brigitte; Huber, Martina Z; Oertle, David; Hilty, Lorenz M (2015). An information system supporting cap and trade in organizations. In: Hilty, Lorenz; Aebischer, Bernard. ICT Innovations for Sustainybility. Cham: Springer, 285-299.

DOI: https://doi.org/10.1007/978-3-319-09228-7_17 


\title{
An Information System Supporting Cap and Trade in Organizations
}

\author{
Brigitte Maranghino-Singer ${ }^{1}$, Martina Z. Huber ${ }^{2}$, David Oertle ${ }^{2}$, \\ Marc Chesney ${ }^{1}$, and Lorenz M. Hilty ${ }^{2,3,4}$ \\ ${ }^{1}$ Department of Banking and Finance, University of Zurich, Zurich, Switzerland \\ \{brigitte.maranghino, marc.chesney\}@bf.uzh.ch \\ 2 Department of Informatics, University of Zurich, Zurich, Switzerland \\ \{mhuber, hilty\}@ifi.uzh.ch \\ ${ }^{3}$ Empa, Swiss Federal Laboratories for Materials Science and Technology, St. Gallen, \\ Switzerland \\ ${ }^{4}$ Centre for Sustainable Communications CESC, KTH Royal Institute of Technology, \\ Stockholm, Sweden
}

\begin{abstract}
We present a software system to create and implement internal markets in organizations that want to limit the $\mathrm{CO}_{2}$ emissions or the use of scarce resources by their employees. This system can be applied to domains such as business travel by distributing a limited number of permits for business travelrelated $\mathrm{CO}_{2}$ emissions at the beginning of a period and then allowing the permits to be traded inside the organization. The system calculates the $\mathrm{CO}_{2}$ emissions caused by planned trips and provides the market mechanisms to trade the permits. The approach can be generalized from emission permits to any scarce good that is assigned by the management to units or individual members of the organization, such as parking spaces. Both cases are described by way of detailed examples.
\end{abstract}

Keywords: Cap and Trade, Emissions Trading, Carbon Dioxide, Corporate Social Responsibility, Corporate Environmental Management Information System

\section{Introduction}

The cap-and-trade principle introduced as an instrument of climate policy can be applied at the intra-organizational level when an organization decides to limit or reduce the emissions caused by its activities. The process of trading emission permits among the members of the organization must be supported by an easy-to-use software system to avoid the administrative overhead of such an internal market. We describe such a software system that can be applied, for example, to the domain of business travel, by distributing a limited number of permits for business travel-related $\mathrm{CO}_{2}$ emissions at the beginning of a period (e.g., the financial year) and then allowing the permits to be traded among the members of the organization, supported by the system, which both

This Accepted Author Manuscript is copyrighted by Springer. The final publication will be available via http://link.springer.com/bookseries/11156 by end of August 2014. Suggested citation: Maranghino-Singer, B., Huber, M.Z., Oertle, D., Chesney, M., Hilty, L.M.: An Information System Supporting Cap and Trade in Organizations. In: Hilty, L.M., Aebischer, B. (eds.) ICT Innovations for Sustainability. Advances in Intelligent Systems and Computing 310. Springer International Publishing (2014, in press) 
calculates the $\mathrm{CO}_{2}$ emissions caused by planned trips and provides the market mechanism to trade the permits.

One advantage of our approach is that it can be generalized from emission permits to any scarce good that is assigned by the management to units or individual members of the organization, such as parking or office space. Depending on the type of good to be traded, different market mechanisms can be used. The current implementation supports call market auctions (in particular, for $\mathrm{CO}_{2}$ emission permits related to business travel) and English auctions (in particular, for the use of parking spaces). The English auction can also be used to create the initial distribution in a call market auction.

We will first describe the cap-and-trade principle (Section 2) and then show the application of the system by way of two examples (Section 3).

\section{Organization-Internal Cap and Trade}

According to the IPCC report 2013, the first decade of the $21^{\text {st }}$ century was the warmest in a very long time. Also, most of global warming seems to be due to human activities. Greenhouse gas emissions are changing the global climate with increasingly severe consequences for mankind, the economy, and the environment. For this reason, reducing greenhouse gas emissions is absolutely essential.

One possible tool for accomplishing this task is emissions trading. For example, in 2005 the EU launched the EU Emissions Trading System (EU ETS), which functions according to the cap-and-trade principle, as a cornerstone of its strategy for costeffective reduction of greenhouse gases. The general workings of such a cap-andtrade system have been described in [1] as follows.

In a cap-and-trade mechanism a quantity of pollution is fixed a priori by the responsible authorities, after a complete assessment of the maximum bearable level of damages. This quantity, called the cap, is set (with great hopes) to replicate the optimal level of pollution as the optimum between the social disutility of pollution and the cost of abatement for the polluting firms. In a way, the agencies that determine the cap can be seen as representatives of a society whose marginal social cost is perfectly elastic: the damages are infinitely sensitive to the smallest variation of pollution.

Once the cap is set, tradable units of pollution are created and allocated to the polluter either for free (grandfathering) or through a compensation scheme. Polluting firms are then allowed to trade those permits among themselves as in the pure market. If many firms have smaller abatement costs than the permit price, they will abate and sell the corresponding permits to firms with higher abatements costs. These sellerinitiated trades will progressively lower the permit price. Conversely, if many firms have higher abatement costs than the permit price, they will buy permits on the market. These buyer-initiated trades will push the price higher.

At equilibrium (when all firms are satisfied), using a market ensures that compliance with the capped pollution level is achieved at the lowest possible cost, since the permit price is equivalent to the lowest possible marginal cost of abatement. Moreo- 
ver, by offering the opportunity to sell permits and generate profits, markets incentivize competitiveness and technology changes towards clean activities.

In the case of the EU Emissions Trading System, however, some problematic aspects of this system have also come to light. Since too many permits were issued from the beginning, the price for a ton of $\mathrm{CO}_{2}$ settled at a level that was too low. As a result, there was no real incentive to reduce $\mathrm{CO}_{2}$ emissions. While it is true that from 2008 on, the number of permits on the market was decreased in response, this did not have the desired effect on the price since the demand for $\mathrm{CO}_{2}$ permits also dropped because of the broadening economic crisis. The price is approximately 5 Euros per ton of $\mathrm{CO}_{2}$ (February 2014), which does not provide a financial incentive to reduce $\mathrm{CO}_{2}$ emissions. Yet it certainly would be possible to address this problem by reducing the number of permits on the market to such an extent that it would actually be possible to increase their price and therefore to achieve the climate goals.

But there is another factor hindering achievement of these climate goals. Thirtyone countries including Iceland, Liechtenstein, and Norway, in addition to twentyeight EU countries, are participating in the EU ETS, which means that more than 11,000 industrial and energy companies are involved, and the program has been expanded to include aviation since January 1, 2012. As a result, the EU is confronted with lobbies from various sectors, in particular aviation, and must stand up to them with the necessary vigor or risk watering down the system in accommodating these various lobbies' individual interests.

Such a cap-and-trade system is applicable not only at the macro level for trading emission permits between different companies but could be put into practice at the micro level within a single private or public institution. Tradable units could be greenhouse gas emission permits as well as rights to use scarce goods, such as parking spaces or conference rooms.

A cap-and-trade system internal to a company might look like the following, using greenhouse gas emission permits as an example: Management defines a maximum yearly permissible cap of $\mathrm{CO}_{2}$ emissions for business trips at $80 \%$ of expected emissions for the following year, with the goal of actually achieving a reduction in $\mathrm{CO}_{2}$ emissions. Then, emission permits are created, each of which permits the holder to emit a certain amount of $\mathrm{CO}_{2}$ (e.g., $100 \mathrm{~kg}$ of $\mathrm{CO}_{2}$ emissions per individual permit), distributed among the individual units within the organization, possibly free of charge, and traded freely on a market internal to the company. If a unit requires more permits than it received for its business trips, it must purchase additional permits on the company-internal market. In the opposite case, it can sell permits it does not need. The price for the permits results from supply and demand on the internal permit market. If, at the end of an accounting period (e.g., at the end of the year), an organizational unit has generated more $\mathrm{CO}_{2}$ emissions on its business trips than its permits allow, it must attempt to purchase additional permits on the company-internal market. If this is no longer possible because permits are scarce, the unit must pay a fine and purchase the missing permits retroactively at the beginning of the following year.

But if the unit has a surplus of permits because its trips generated a smaller amount of $\mathrm{CO}_{2}$ emissions, it can try to sell these permits to other departments. The income from such permit sales could be used, for example, in the following ways: 
- as a bonus paid to the staff members of the relevant department, which thus creates an additional incentive to reduce $\mathrm{CO}_{2}$ emissions;

- to increase the discretionary budgets of those staff members whose $\mathrm{CO}_{2}$ emission reductions made it possible to sell permits;

- to build up the departmental fund available for team-building events;

- to improve the infrastructure of the department in question, whether by reducing $\mathrm{CO}_{2}$ emissions further and/or improving staff members' job satisfaction;

- as a reserve for future discretionary expenses by the department in question; or

- for a combination of the items mentioned above.

This would make it possible not only to reduce the emissions generated by staff members, but also to utilize the potential for associated cost reductions. The same market mechanism would also enable cost-effective internal distribution of the scarce goods mentioned above.

A software system [2,3], which will be described in the next section, is required to make good use of the potential of such a company-internal cap-and-trade system.

\section{An Information System Supporting Organization-Internal Cap and Trade}

\subsection{System Architecture and User Roles}

The system has a web-based software architecture, which means that each user can $\log$ into the system via a web browser from any computer without the need to install software. There are five user roles with different functions and access rights:

- Market participant: An individual or group who owns permits and trades these permits on the internal market. Market participants may have received the permits from their department head in the initial allocation or they may have purchased them on the market. Whenever they use (consume) permits, they must register the consumption in the system (charge their account of permits).

- Agent: An agents has access to the accounts of market participants he or she acts for. Agents are only needed if market participants want to delegate the interaction with the system. A single agent can act on behalf of many market participants.

- Consumer: An individual who belongs to a group owning permits. Consumers can consume permits and debit the consumption from the group account, but cannot trade on their own behalf. Each consumer is assigned to a market participant who is responsible for the trading. For example, the head of group could take the role of the market participant for all group members, because he or she has to approve their business trips anyway.

- Department head: This role is only relevant for the initial distribution of permits at the beginning of each trading period (e.g., the financial year). A department head distributes permits assigned to the department among the groups or individuals within in the department. 
- Administrator: The Administrator sets up the market by deciding what can be traded with which market mechanisms and defines the initial allocation of permits among the departments.

As the preferred names of the user roles may differ from organization to organization, the identifiers used by the system can be reconfigured when the system is set up.

\subsection{Business Trip Examples}

Introduction. The following two examples highlight the internal online cap-and-trade platform from a market participant's perspective. To make the examples more concrete, system settings are defined as follows:

- 1 permit equals 1 emitted $\mathrm{kg}$ of carbon dioxide $\left(\mathrm{CO}_{2}\right)^{1}$.

- The period starts on January 1 and lasts 12 months until December 31.

- Each employee gets 5760 permits at the beginning of a period.

- The amount of 5760 permits corresponds to $80 \%$ of 7200 permits. $7200(12 \times 600)$ are emissions expected for the following year assuming that every business trip that has to be taken by plane is an economy flight and that for all other business trips the small car category is the chosen alternative

- For the examples, we use a virtual currency: Mundo

The (fictional) company AirPower is specialized in worldwide consulting for finding the best possible locations for wind farms. The headquarters of AirPower is located in Zurich, Switzerland, where currently 200 consultants are employed. For their business trips, consultants can choose among different modes (train, car, plane) and are free to decide which route they want to take.

Example I shows Peter's traveling decision process for his next meeting with a possible future client in Munich, Germany. Example II shows Zoe's decision process for her next trip to San Francisco, United States, where she will discuss further steps of the ongoing project with the local authorities.

Example I. As the first step in planning his trip, Peter selects Car as his mode of transportation (Fig. 1). After entering the starting point (Zurich) and the destination (Munich), he selects his preferred car type among a selection of car types offered by the internal online cap-and-trade platform. The selection is important for the calculation of the $\mathrm{CO}_{2}$ emissions. Peter checks the category for high-end cars. Next, he checks the box for a return trip and enters the date of his travel (October 5, 2014) (Fig. 2).

1 The life cycle assessment data provided by ecoinvent [5], which is used by our system, takes into account all relevant greenhouse gases. The emissions are therefore calculated in $\mathrm{kg} \mathrm{CO}_{2}$ equivalents $\left(\mathrm{kg} \mathrm{CO}_{2} \mathrm{eq}\right)$. For simplicity, however, they are presented to the user as $\mathrm{kg} \mathrm{CO}_{2}$. 


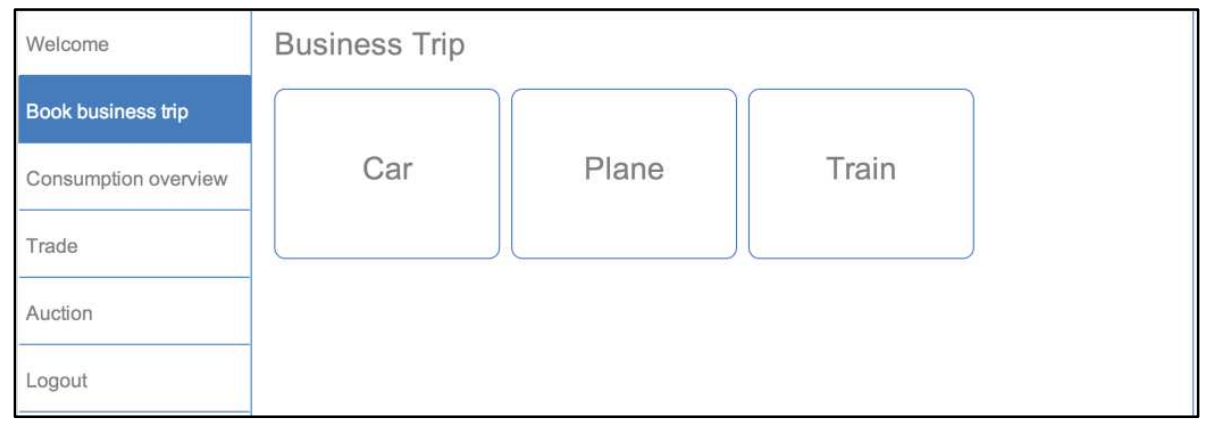

Fig. 1. Selecting means of transportation

Expected $\mathrm{CO}_{2}$ Emissions by Mode of Transportation. He clicks Preview and immediately a sketch of his trip is shown on a map on the right of the screen (Fig. 2). Beneath the map, a summary of the one-way trip shows the starting point, the destination, the car category and the travelling distance [4]. At the end of the list, CO2 Emission for Round-Trip indicates the estimated amount of emitted $\mathrm{CO}_{2}(274 \mathrm{~kg})$ in case the driver returns the same way.

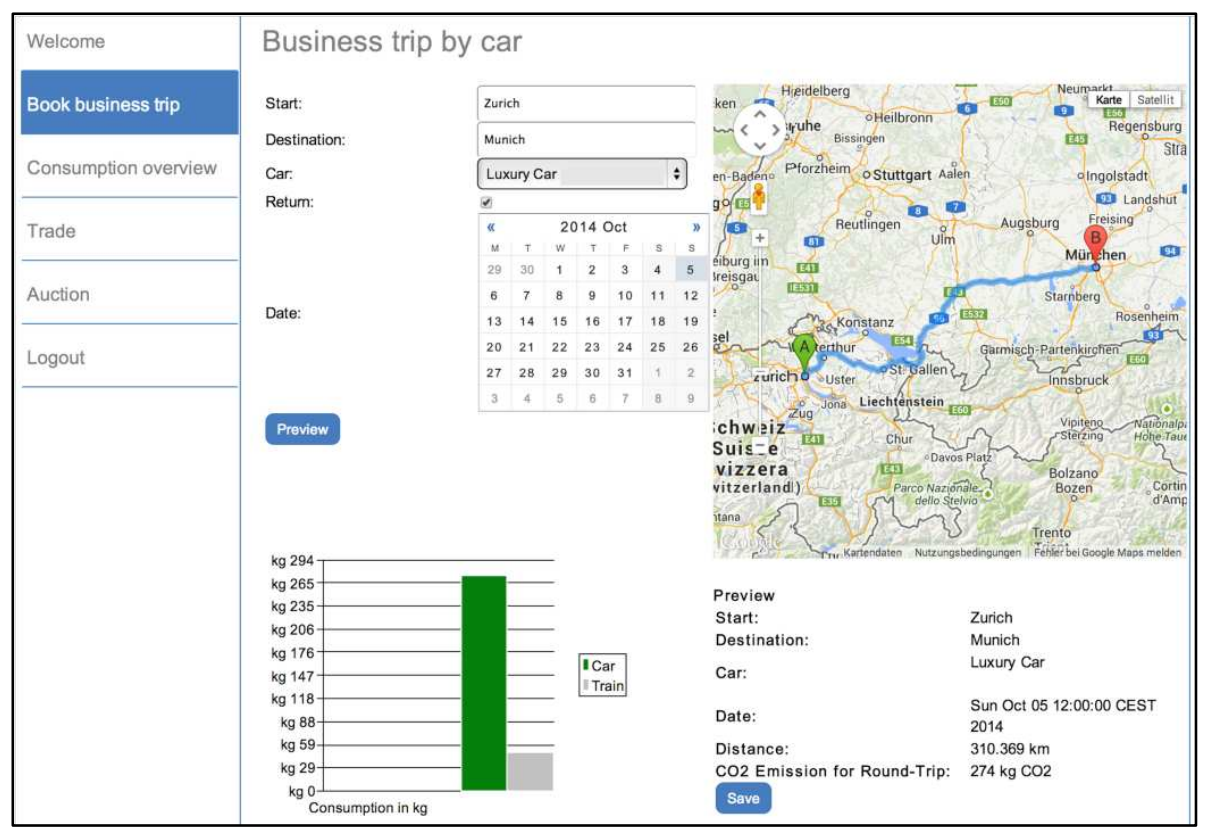

Fig. 2. Calculated $\mathrm{CO}_{2}$ emissions [5] assuming a luxury car

Amazed by the high value and considering the rather short travelling distance, he decides that a smaller car (Minicar) will do just as well. The new result (184 kg; Fig. 3) suits better with him. 


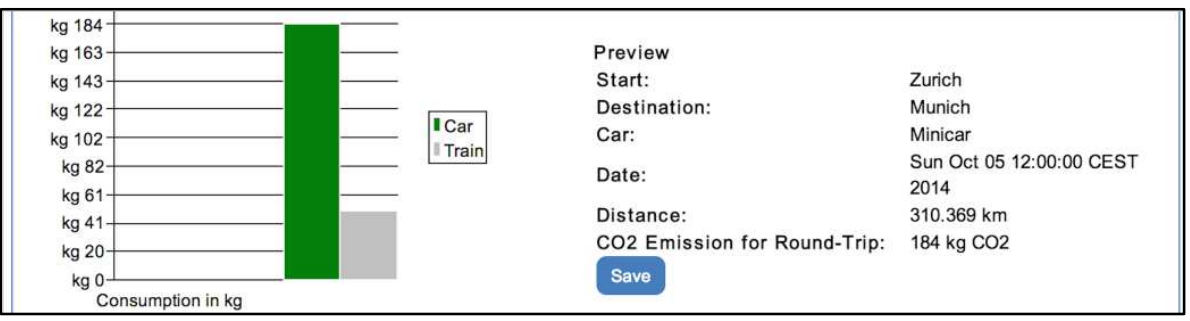

Fig. 3. Calculated $\mathrm{CO}_{2}$ emissions [5] assuming a small car

By taking the smaller car, Peter would emit $90 \mathrm{~kg}$ less $\mathrm{CO}_{2}$ and save 90 permits. Before clicking Save Peter notices the bar chart on the left side at the bottom of the page. The chart shows the total $\mathrm{CO}_{2}$ emissions of the selected car (left bar) as well as Peter's expected emissions for the same trip if he takes the train (right bar). The difference looks huge.

Peter saves the planned car trip but wants to know more details about traveling by train. Therefore, this time he chooses Train from the selection provided (Fig. 1). After he enters all relevant information, the preview shows the calculated emissions for a trip by train (48 kg; Fig. 4). Compared to the solution with the luxury car, he would save $226 \mathrm{~kg} \mathrm{CO}_{2}$ (equals 226 permits), while he would save $136 \mathrm{~kg} \mathrm{CO}_{2}$ (equals 136 permits) compared to the solution with the small car. The bar chart now compares the $\mathrm{CO}_{2}$ emissions from the train with those from an average European car.

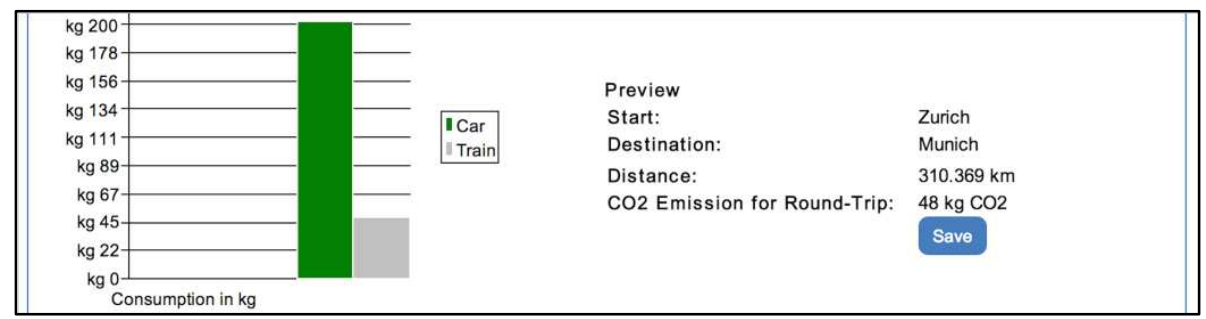

Fig. 4. Calculated $\mathrm{CO}_{2}$ emissions [5] assuming passenger train

He decides to take the solution with the train and saves it. Now he has to cancel the prior saved solution in which he had chosen to travel by car. Therefore, he selects Consumption overview in the navigation pane (e.g., Fig. 2).

The internal online cap-and-trade platform shows a list of all future trips. After Peter has cancelled the planned car trip to Munich (by clicking the " $x$ " on the right side), the list looks as shown in Figure 5. 


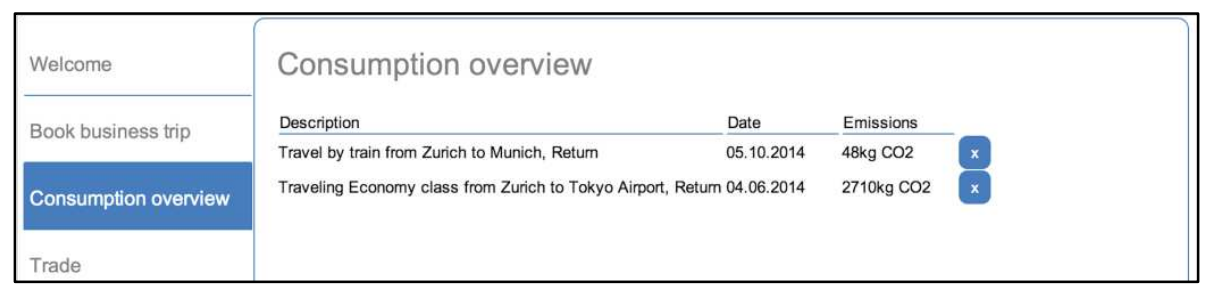

Fig. 5. Consumption overview

Trading $\mathrm{CO}_{2}$ Emission Certificates. Peter decides to trade the $136 \mathrm{CO}_{2}$ permits he saved by taking the train instead of the small category car over the company's internal market. Therefore, he chooses Trade on the left (e.g. Fig. 6). The screen shows the overview (Fig. 6). According to the value of Available permits, Peter has already used 558 permits (the initially distributed 5760 minus the currently available 5202). The value of Needed permits results from his flight to Tokyo (2710) and for his trip to Munich (48) (Fig. 5). Current balance shows the amount of money spent (negative balance) or gained (positive balance) by trading permits. Since Peter has not been trading until now, his current balance is 0 .

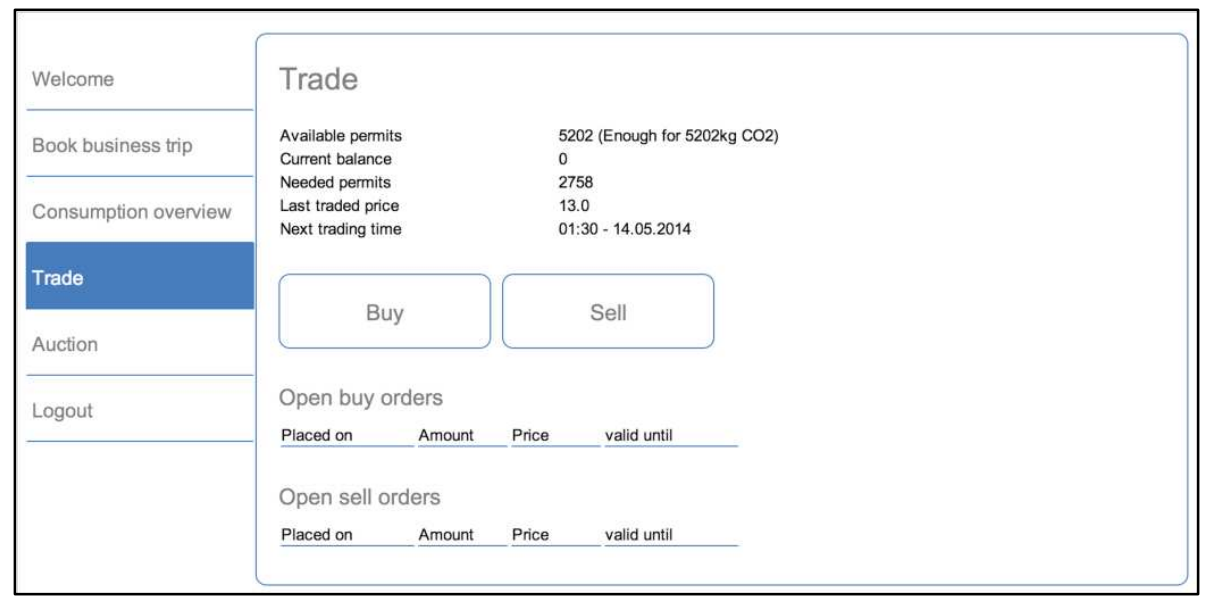

Fig. 6. Trading $\mathrm{CO}_{2}$ emissions - overview

He chooses sell (Fig. 6) and a pop-up window appears (Fig. 7). Within the pop-up window he enters the number of permits he intends to sell (136) and the minimum price (13 Mundo) into the corresponding fields. Finally, he selects the date until his offer will be valid (May 30, 2014). 


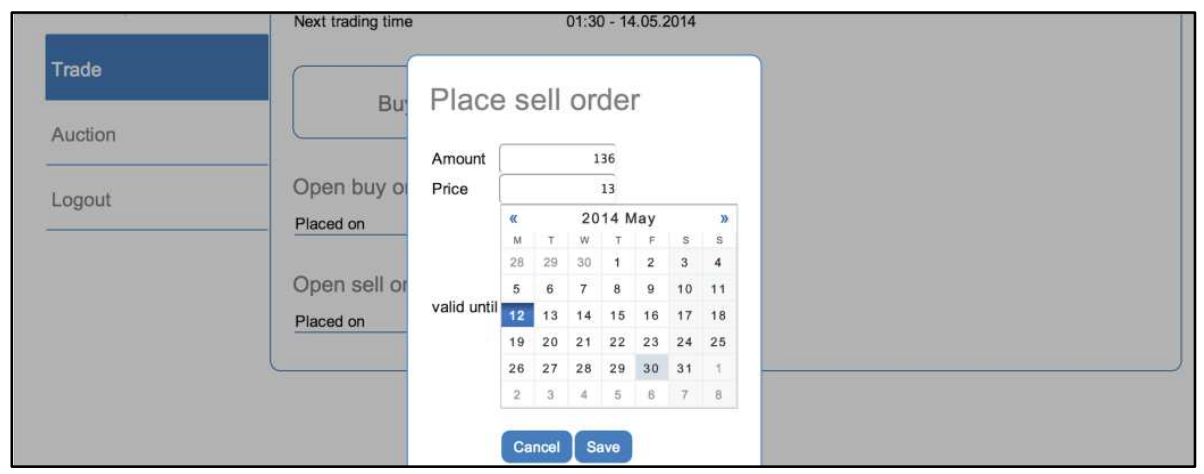

Fig. 7. Trading $\mathrm{CO}_{2}$ emissions - placing an order

After he saves his order, it appears in the overview as open sell order (Fig. 8).

Peter found one buyer and earned 1768 Mundo $(13 \times 136)$. According to the company's policy, the profit he is going to make by the end of the year is given to him as an additional payment to his public transportation season pass. As mentioned above, many policies for dealing with a surplus or deficit that occurs at the end of the year are possible.

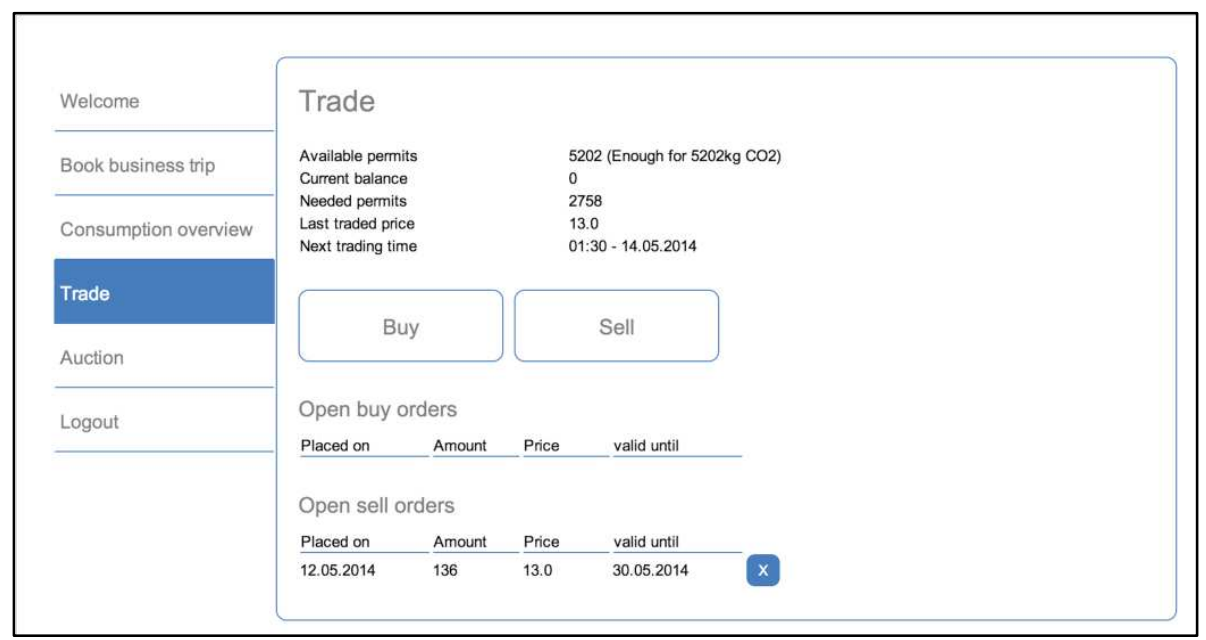

Fig. 8. Trading $\mathrm{CO}_{2}$ emissions - open orders 
Example II. For her business trip to San Francisco, Zoe chooses Plane as the mode of transportation (Fig. 1). After filling in all required data and clicking Preview, she sees the start and end destination on the map on the right of the screen (Fig. 9). ${ }^{2}$

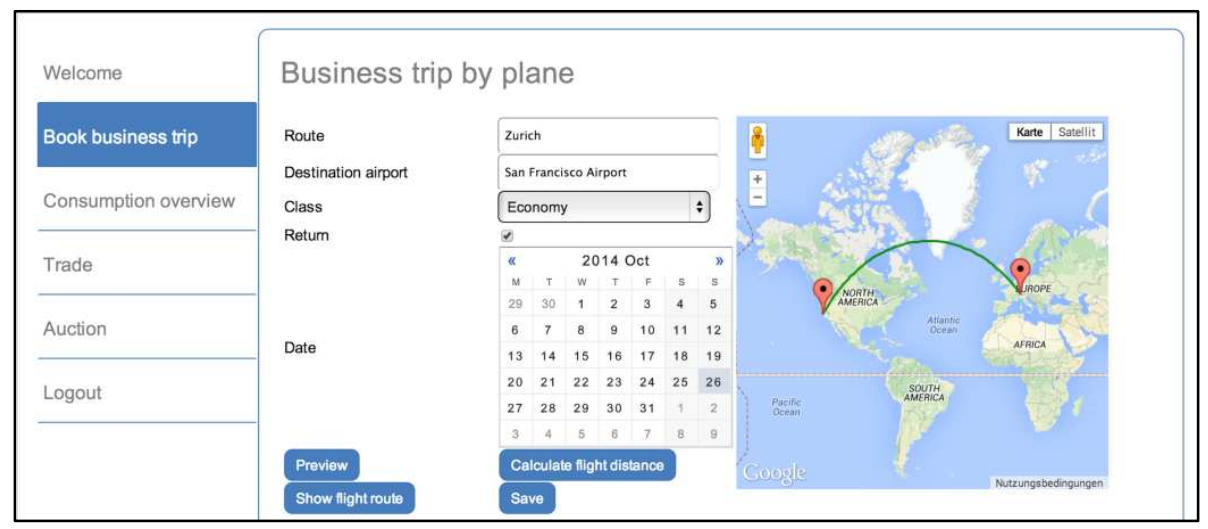

Fig. 9. Preview of business trip by plane

The button Show flight route generates a list of possible outbound or return flights, both direct and with stopovers. Figure 10 shows the list of all outbound flights at the chosen date (October 26, 2014) with specific information on the selected flight about the airline, the travel distance [6] and the amount of emitted $\mathrm{CO}_{2}$. Different distances for the same flight can show up in case of different routes taken for the second leg of the flight (e.g., due to air traffic conditions). For example, within Fig. 10 the connecting flight AA65 flies from Zurich to New York from which point one can decide between three different connecting flights (\#6 and \#7 vs. \#10).

Zoe compares the $\mathrm{CO}_{2}$ emissions of the non-stop flight \#12 with the connecting flight \# 6 (Fig. 10). The non-stop flight emits $1224 \mathrm{~kg} \mathrm{CO} 2$ (Fig. 10) and the connecting flight $1405 \mathrm{~kg} \mathrm{CO}_{2}$ (Fig. 11). The connecting flight makes a stop in New York, which would give her the opportunity to meet another business partner. However, since she already had to fly overseas this year, she decides to save the 181 permits by taking the direct flight. To communicate with her business partner in New York, she sets up an online meeting, which now will take place during her stay in San Francisco. In this way she has a threefold advantage: She saves $\mathrm{CO}_{2}$ emissions, saves permits and the time difference between her business partner's location and hers is smaller compared to when she is in Zurich.

2 It would also be possible to choose a business class flight, resulting in significantly higher emissions (per person) compared to the economy flight. 


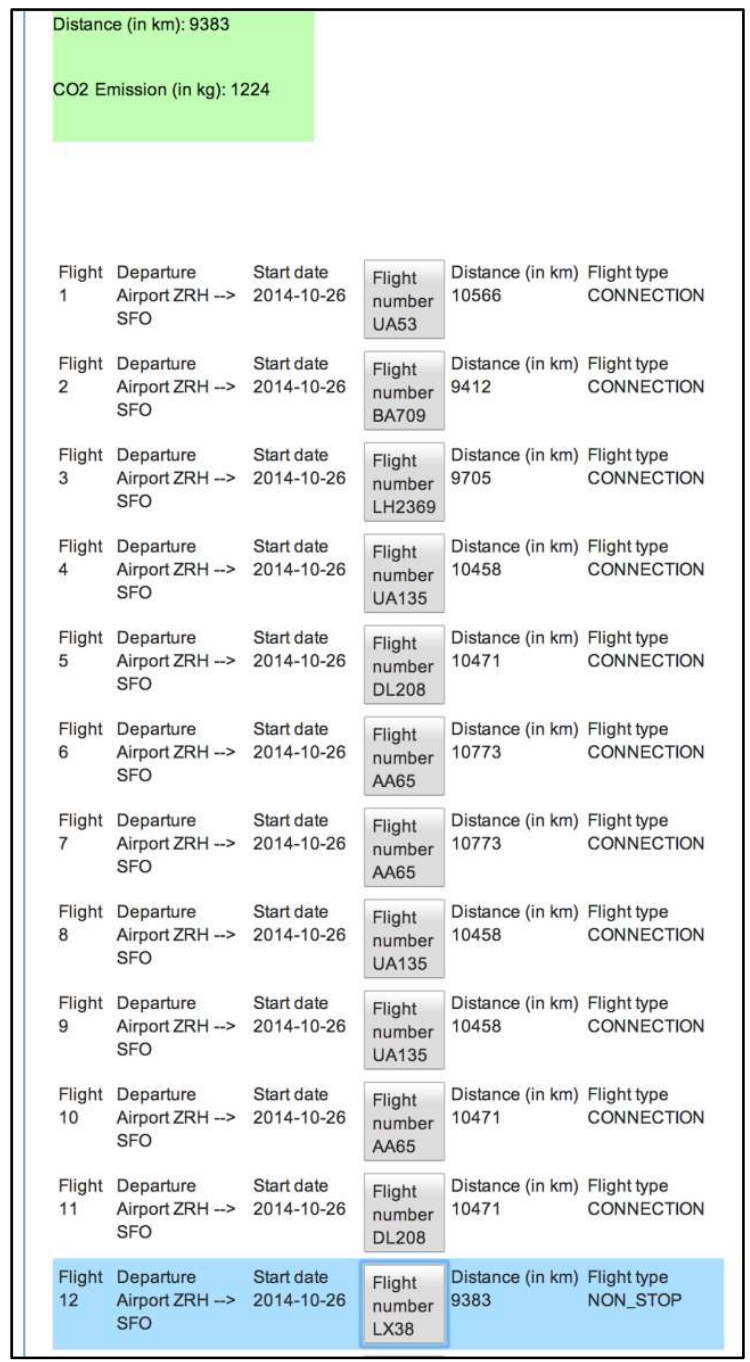

Fig. 10. Calculated $\mathrm{CO}_{2}$ emissions [5]: nonstop flight \#12

Distance (in km): 10773

CO2 Emission (in kg): 1405

Fig. 11. Calculated $\mathrm{CO}_{2}$ emissions [5]: connecting flight \#6 


\subsection{Parking Lot Example}

Introduction. The following is an overview of the functionality of the auction mechanism of the internal online cap-and-trade platform. To make the example more comprehensive, it is described from a market participant's perspective. Specific system settings, such as how the amount of money is transferred from one employee to another, depend on companies' regulations and are entered by the system administrator. No further details are provided here.

In the following example the auction is for parking lots; however, in conformance with company regulations any kind of asset (e.g., meeting rooms, coffee machines, printing paper) can be defined.

The (fictional) company WhiteMoney is a financial institute whose headquarters, which employs 800 people, is located in Geneva, Switzerland. Around one-third of the staff drives regularly by car to work, but the capacity of the company's parking lot is limited to 150 cars. In the following we spotlight Marianna, lucky owner of a parking space in this lot, who will be on vacation next week; and John, who urgently needs a parking space on a specific date. Both will participate in an English auction organized via the internal online cap-and-trade platform. ${ }^{3}$

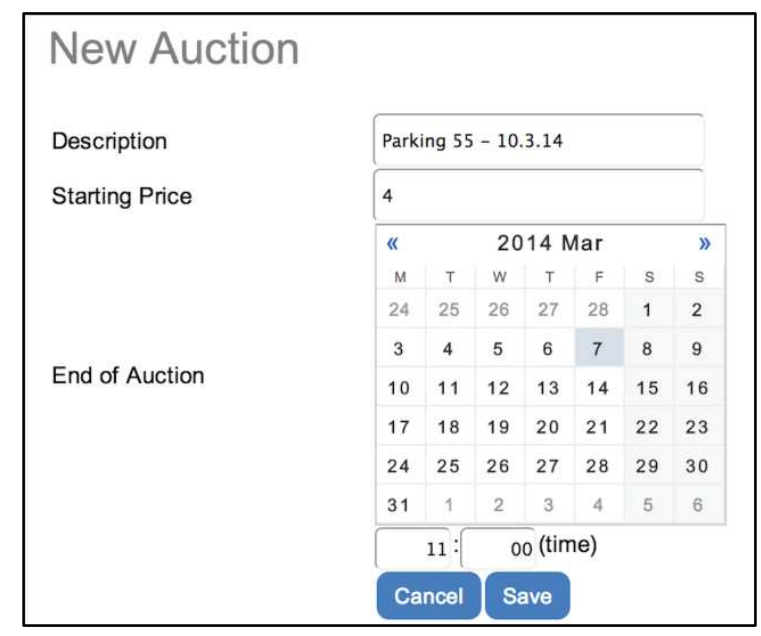

Fig. 12. Auction information

Example. Marianna decides to offer her parking space during her vacation to her coworkers. She chooses Auction on the navigation pane (Fig. 1), creates a new auction by clicking Start new auction and enters all relevant information such as the exact description (Parking 55...), the starting price (4 Mundo) and the date when she wants

3 In an English auction the participants bid openly one against another. Each subsequent bid has to be higher than the previous one. When no participant bids further on the auction ends and the highest bidder must pay his bid. 
the auction to end (March 7, 2014 11:00 am), into the pop-up window (Fig. 12). Before saving, she realizes that parking spaces are often only needed on specific days of the week and therefore decides to start an auction per day. She clicks Cancel and inserts 6 auctions according to the previous schema. Since March 16 is a Sunday, she decides to give the parking space for free on that date.

She assumes one week could be too much time in advance for people to know if they need a parking space. Therefore she decides to change the end date for the three last auctions from March 16 to March 12 (Fig. 13). Since the system will end the auction automatically and advise the winner, she does not have to worry about taking care of this while on vacation. After clicking the Save button (Fig. 12), her auctions (Parking 55 - 1x.3.2014) appear together with her co-worker's auctions on the list "Open auctions" as well as separated in "My auctions" (Fig. 13). "Current balance" (105.0) (Fig. 13) shows the amount of money she currently has available for bidding in auctions.

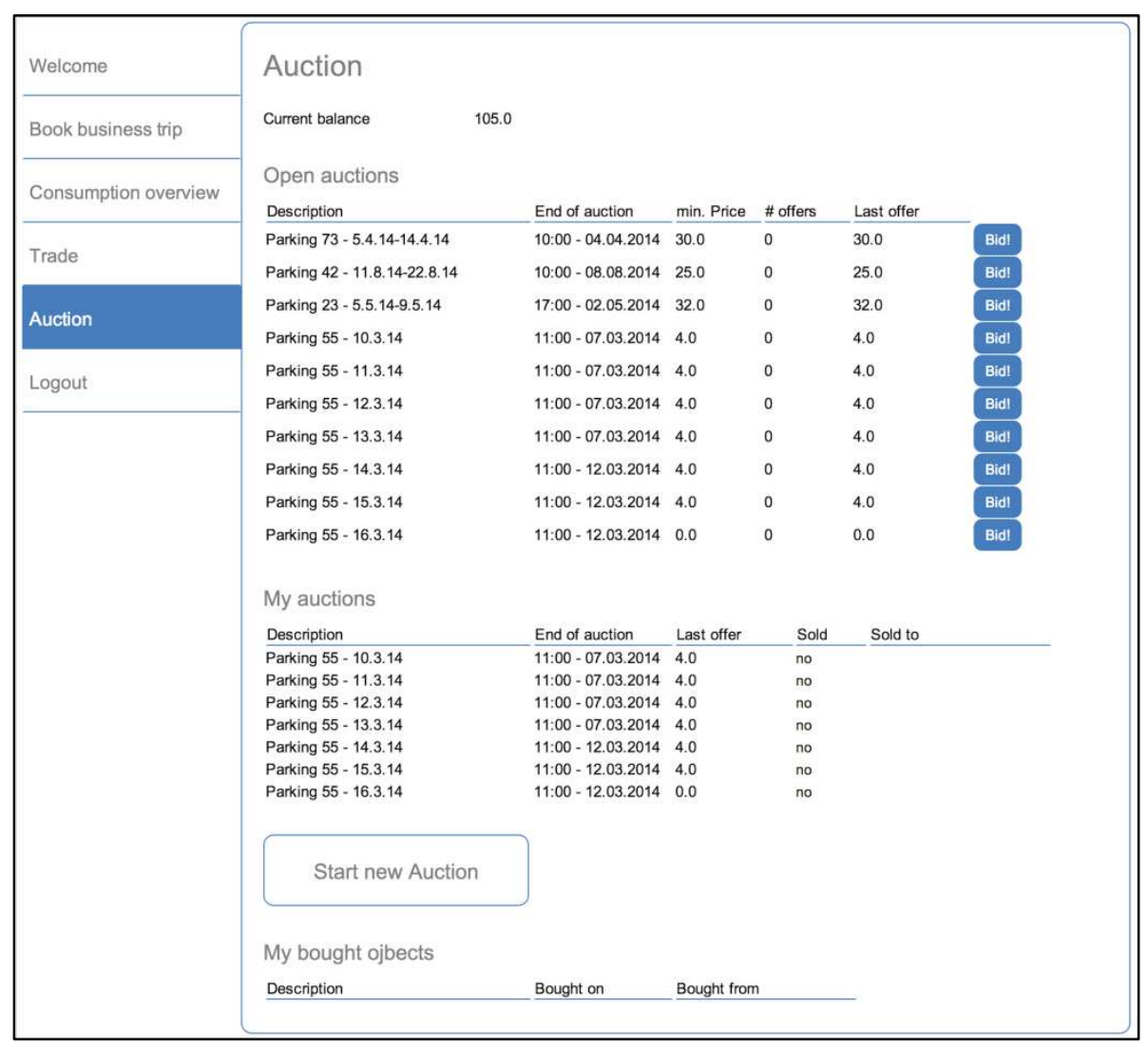

Fig. 13. Marianna's auction overview 
John urgently needs a parking space in the lot for next Tuesday (March 11, 2014) and Thursday (March 13, 2014). He remembers the article about the new internal online cap-and-trade platform in the last issue of the company journal Transparency and decides to try it out. After logging into the system, he chooses Auction (Fig. 1). On the overview (Fig. 14) he sees all running auctions and is lucky; for both Tuesday (March 11, 2014) and Thursday (March 13, 2014) of next week, an auction for parking space 55 is running. The current price for Tuesday is 8 Mundo; it seems to be a busy day since four offers have already been placed.

On Thursday only one offer has been placed thus far. Consequently, the price is lower (5 Mundo). John still has enough money left on his account to participate in both auctions. He clicks Bid! at the right hand side of Tuesday's auction (Fig. 14) and enters a bid clearly above the current price (12 Mundo) into the pop-up window (Fig. 16), hoping to win the auctions. After saving he repeats the same for Thursday's auction.

On March 7 he gets an e-mail generated by the system informing him that he has won the auction for the two dates of interest.

\begin{tabular}{|c|c|c|c|c|c|c|}
\hline \multirow{2}{*}{ Consumption overview } & \multicolumn{6}{|l|}{ Open auctions } \\
\hline & Description & End of auction & $\min$. Price & \# offers & Last offer & \\
\hline \multirow{2}{*}{ Trade } & Parking 73 - 5.4. 14-14.4.14 & $10: 00-04.04 .2014$ & 30.0 & 0 & 30.0 & Bidl \\
\hline & Parking $42-11.8 .14-22.8 .14$ & $10: 00-08.08 .2014$ & 25.0 & 0 & 25.0 & Bidl \\
\hline \multirow{2}{*}{ Auction } & Parking 23 - 5.5.14-9.5.14 & $17: 00-02.05 .2014$ & 32.0 & 0 & 32.0 & Bidl \\
\hline & Parking 55 - 10.3 .14 & $11: 00-07.03 .2014$ & 4.0 & 1 & 8.0 & Bidl \\
\hline \multirow{6}{*}{ Logout } & Parking 55 - 11.3.14 & $11: 00-07.03 .2014$ & 4.0 & 4 & 8.0 & Bidl \\
\hline & Parking 55 - 12.3.14 & $11: 00-07.03 .2014$ & 4.0 & 1 & 7.0 & Bidl \\
\hline & Parking 55 - 13.3.14 & $11: 00-07.03 .2014$ & 4.0 & 1 & 5.0 & Bidl \\
\hline & Parking 55 - 14.3.14 & $11: 00-12.03 .2014$ & 4.0 & 3 & 12.0 & Bidl \\
\hline & Parking 55 - 15.3.14 & $11: 00-12.03 .2014$ & 4.0 & 0 & 4.0 & Bidl \\
\hline & Parking 55 - 16.3 .14 & $11: 00-12.03 .2014$ & 0.0 & 0 & 0.0 & Bidl \\
\hline
\end{tabular}

Fig. 14. John's Auction overview

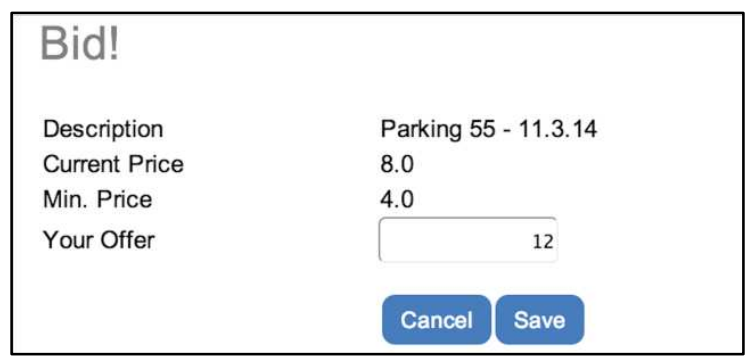

Fig. 15. Auction bid 


\section{Conclusion and Outlook}

In this chapter, we presented a software system supporting the creation and implementation of organization-internal markets for $\mathrm{CO}_{2}$ emission permits and other limited resources that can in principle be optimally allocated if they can be traded.

Thus far, implementations of cap-and-trade systems have focused on the macro level, with the EU ETS in Europe (The European Emission Trading Scheme) in particular. At a micro level, i.e., at the company level, cap-and-trade systems have a huge potential that has been neglected. They could intelligently complement the EU ETS by providing companies the means to comply with current macro regulations. They would help companies reduce their energy costs and therefore not only to abate $\mathrm{CO}_{2}$ emissions but also to generate cash flows by selling their extra emission rights.

This system should be of interest for many companies in different sectors. Confronted with a limited number of offices, parking spaces or a limited travel budget, they should try to optimize their decision making process and rely more on solutions such as car sharing, teleworking or online meetings. On the one hand, the system allows the employees to take more responsibility while on the other hand it gives them incentives to make efficient choices.

\section{References}

1. Chesney, M., Gheyssens, J., Taschini, L.: Environmental Finance and Investments, Springer, Heidelberg (2013)

2. Oertle, D.: Plattform für den Handel von Ressourcen innerhalb eines Unternehmens am Beispiel von CO2-Zertifikaten für Dienstreisen, University of Zurich, Faculty of Economics, 2013. (Master Thesis)

3. Badertscher, S.: Generalisierung des intra-organisationalen Cap and Trade, University of Zurich, Faculty of Economics, 2013. (Master Thesis)

4. Google Maps API. https://developers.google.com/maps/. Accessed 4 May 2014

5. ecoinvent Centre, ecoinvent data v3.0, Online Database. http://www.ecoinvent.org. 2013, Swiss Centre for Life Cycle Inventories: Zürich, CH

6. FlightStats Flex API. https://developer.flightstats.com/api-docs/. Accessed 4 May 2014 